\title{
No Longer Out of Reach: Blended Competency-Based College Models for Accelerating Higher Education for Refugee Students
}

\author{
Meagan A. Hoff ${ }^{1 *}$ and ${ }^{2}$ Khaleel Shreet ${ }^{2}$ \\ ${ }^{1}$ Collin College, USA \\ ${ }^{2}$ Southern New Hampshire University, USA \\ "Correspondence: mhoff@txstate.edu
}

\begin{abstract}
Higher education offers a pathway to gain or recuperate professional credentials, particularly after experiencing forced displacement. Yet only $1 \%$ of refugees pursue postsecondary studies due, in part, to numerous obstacles on that path to college. The purpose of this study was to understand how a competency-based college program facilitates access to college for students from refugee backgrounds. This paper details the findings from a qualitative case study with refugee-background students enrolled in a college program that combines a competency-based model with in-person support. Using the ecological model of college readiness, we found that refugee students benefited from the flexibility of the program and the intensive in-person academic support.
\end{abstract}

Keywords: refugee, competency-based education, academic coaching, college readiness

\section{Introduction}

Narratives about refugees are too often portrayed in deficit terms (Uptin et al. 2016). In contrast to these narratives, among refugees resettling in the United States, $75 \%$ had a high school education and $28 \%$ arrived with college degrees (Capps \& Fix, 2015). As these numbers show, refugees are arriving with years of educational and professional experience that are unseen and undervalued within the United States. Contrary to the claims by the U.S. Department of State (n.d.) that "most refugees will 
move ahead professionally" (para. 7), Batalova et al. (2008) found that they did not return to a level of employment similar to their position before displacement, likely due to barriers in pursuing educational opportunities that could facilitate professional advancements.

Higher education offers a pathway to gain or recuperate professional credentials, particularly after experiencing forced displacement. Yet globally, only $1 \%$ of forcibly displaced individuals pursue postsecondary studies (UNHCR, 2016). Students from refugee backgrounds face numerous obstacles on that path to college including informational barriers (Bajwa et al., 2017), competing priorities (Crea, 2016), and language barriers (Kanno \& Varghese, 2010). The educational outcomes of refugees in the United States diminish as age of arrival increases (Evans \& Fitzgerald, 2017), meaning that those who resettle as adults face even greater barriers.

Long-standing deficit-framing of refugee-background students further exacerbate inequities. Common narratives around refugees are a product of underlying assumptions about refugees as illiterate, undereducated, and helpless while fueling policies that threaten to make these assumptions self-fulfilling by restricting access to educational opportunities (Zeus, 2011). Current policies in the United States are riddled with obstacles to pursuing a postsecondary education, which research indicates is crucial to achieving the overarching goal of preparing people to rebuild their home communities (UNHCR, 2016).

There is a clear need to understand how refugees can overcome these obstacles and yet very little research has focused on facilitating pathways into higher education, specifically for refugees who resettled as adults. Although there is a great deal of research on the educational needs of refugee children (see, for example, McBrien, 2005), adults face distinctly different obstacles in pursuing an education. The purpose of this study was to understand how a competency-based college program facilitates access to college for students from refugee backgrounds.

\section{Literature Review}




\section{An Ecological Model of College Readiness}

Access to, and success in, college programs often requires a particular set of pre-established academic experiences, skills, and dispositions acquired through years of public schooling. For students from refugee backgrounds, their past experiences can be quite diverse. To understand the role of the competency-based program in facilitating access to college, we drew on Arnold and colleagues' (2012) Ecological Model of College Readiness. Arnold proposed a model of college readiness with five key elements that influence academic preparedness: academic skills and discipline, college knowledge, selfefficacy, aspirations, and motivation. Academic skills and discipline refer to the mastery of key core concepts and expected ways of thinking and behaving (Conley, 2010). College knowledge is an understanding of what college is and how it works (Conley, 2005). Self-efficacy is the belief about one's own abilities (Bandura, 1997). Aspirations refer to a student's desire to attend college (Arnold et al., 2012). Finally, Arnold et al. (2012) defined motivation as one's "orientation toward engaging challenges" (p. 20). In the ecological model of college readiness, each element is vital in developing college readiness. Rather than viewing students as having or lacking in these key elements, the model posits that adequate resources and support could help students develop the requisite skills to be successful. Yosso's (2005) Community Cultural Wealth framework offers an expansion to this ecological model by providing an asset-based lens that better captures the strengths of students from non-dominant backgrounds. Yosso (2005) outlined six forms of cultural wealth, or capital, that frame the experience of students in accessing college. Aspirational capital refers to the hopes and dreams held by the student and the ability to maintain and pursue those goals. Linguistic capital includes various languages and ways of communicating. Familial capital refers to the cultural knowledge shared within families and communities. Social capitals are social networks and community resources. Navigational capital includes the knowledge, skills, and ability needed to navigate social institutions, including educational spaces. 
This perspective frames college readiness as social and cultural whereas Arnold et al. (2012) frame readiness in terms of individualized traits.

\section{Pursuing Higher Education After Forced Migration}

Research has examined barriers to college access (Perry \& Mallozzi, 2011), but there has been minimal focus on factors that lead to persistence. Complications resulting from forced migration and restrictive resettlement policies make refugee-background students particularly susceptible to four common barriers to persistence: sociocultural, economic, academic, and situational (Babineau, 2018). Similar to first-generation students, refugees are less likely to have the social and cultural capital that can help them navigate complex new educational spaces. Economically, the cost of higher education is high overall. For refugees, who are simultaneously rebuilding lives and careers, these financial barriers can be overwhelming and there is minimal financial aid directly targeting refugee-background students. Economic barriers can compound with sociocultural barriers given the complexities of financial aid. Academically, refugee-background students must adapt to new educational systems, often while learning a new academic language. Time in American schools can help refugee-background students navigate academic expectations (Hoff, 2020) but refugee-background students receive minimal support in understanding new school systems (Morrice, 2013). The situational aspects engendered by forced migration and resettlement can also complicate access and persistence. American resettlement policies focus on immediate employment, which restricts access to postsecondary education (Perry \& Mallozzi, 2011). Like nontraditional students more broadly, refugees are more likely to be balancing work and school.

Deficit perspectives often focus on what refugee-background students lack academically, over what they contribute to their new communities (Shapiro \& MacDonald, 2017). Refugees have rich linguistic repertoires that are often devalued in American schools (Morrice, 2013). By framing academic literacies as strategic rather than purely skills-based, Hoff (2020) illustrated the agentive ways that refugee- 
background students navigate new academic contexts and expectations. For students pursuing higher education, there are many factors that could influence academic success. Unfortunately, refugeebackground students have received very little attention in research, policy, or practice at the college level. New and innovative approaches are needed to help address the barriers to college access and persistence.

\section{Competency-Based Learning}

In recent years, the U.S. higher education system has been navigating several challenges pertaining to rising costs, under-preparedness of graduates, deficiencies of learning assessment, and meeting the needs of an increasingly diverse population (Laitinen, 2012). One of the major alternative models proposed and adopted to challenge the status quo is competency-based education (CBE, alternatively mastery, proficiency, or performance-based learning) (Laitinen, 2012). CBE has gained a resurgence of interest among U.S. higher education institutions as an alternative model, particularly upon the U.S. Department of Education's (2013) approval of using direct assessment of student learning in lieu of traditional credit hour measurements while remaining eligible for accreditation and Title IV funding. The U.S. Department of Education (2013) recognized the potential of CBE programs to offer innovative pathways for quality and affordable college degrees that can flexibly accelerate students' progress to accredited degrees.

CBE programs do not follow a prescriptive model, but Gervais (2016) attempted to construct a unifying operational definition explaining that, at its foundation, $C B E$ is "an outcome-based approach to education that incorporates modes of instructional delivery and assessment efforts designed to evaluate mastery of learning by students through their demonstration of the knowledge, attitudes, values, skills, and behaviors required for the degree sought" (p. 99). CBE programs untether from the standard credithour provisions where they bring learning expectations to a fixed level and leave time spent in education settings to become the variable (Elam, 1971). Learning outcomes are embedded in 
competencies, which stands for "the capacity to perform successfully in an academic, professional, or social environment" (Cañado, 2013, p. 4). Mastery of these competencies, being a fundamental requirement of program completion, promotes deep learning, and ensures graduates' readiness to tackle future education and employment challenges (Krauss, 2017).

Several implied elements of CBE programs theoretically position them to effectively address some of the reviewed systematic challenges refugees face in higher education. The personalized pacing of these programs may be particularly beneficial to refugee students who often have more diverse educational trajectories compared to traditional university students (Castaño Muñoz et al., 2018). With a transparent focus on outcomes, these programs provide enrollment flexibility by holding students accountable for exit performance and institutions accountable for learning and career-readiness (Elam, 1971). To facilitate learning and increase the self-pacing efficacy of CBE, programs often utilize projectbased modularization of outcomes with adaptive and personalized feedback loops (Elam, 1971).

Students access the needed learning resources and utilize prior knowledge to progress through projects and competencies at their own pace rather than a predetermined schedule (Hernen, 2016; Yang, 2012). Given the innovative design, programs using CBE may offer a means of removing barriers that often impede the educational advancement of students from refugee backgrounds; however, there is limited research available on the use of CBE with students from these backgrounds. Working with refugees globally, Russell and Weaver (2019) argued that online-only learning models were not sufficient for refugee populations and promoted instead, a blended model that pairs in-person support with CBE. Russell and Weaver (2019) conducted a case study from the perspective of program administration. Our goal was to build on their work by examining the perspective of refugee students in a blended CBE program.

\section{Methodology}


To understand if a competency-based model helps eliminate obstacles for refugee students, we conducted a case study (Merriam, 1998) at the Pair program (Program and participant names are pseudonyms) that combines a competency-based college program with in-person support. Students in the program are enrolled in an online CBE model while receiving in-person, wrap-around support through academic coaching and weekly group meetings. Pair also provides a low-cost option for college because students can accelerate through credits more quickly. In contrast to traditional semester-based courses, students in Pair progress through competencies by completing projects. They can edit and resubmit projects until they are considered mastered-defined as A-level work. During data collection, the program had about 340 students enrolled, many of whom identified as arriving in the U.S. as migrants; the student population was diverse.

\section{Participants}

This paper focuses on three students from a larger case study-Tommy, Danny, and Yannick. These three participants were chosen because they represented a variety of experiences including country of origin, level of education prior to displacement, and experiences in U.S. schooling (see Table 1).

\section{Table 1}

Participant Demographic Information

\begin{tabular}{lccc}
\hline & Tommy & Danny & Yannick \\
\hline Country of Origin & Iraq & Bhutan & Burkina Faso \\
\hline Level of education pre- & Some college & Middle school & Bachelor's Degree \\
displacement & & High school and & One semester online \\
\hline Experience in US & English courses & community college & college program \\
schooling & & Adolescent & Adult \\
\hline Approximate age of & Adult & & \\
arrival & & & \\
\end{tabular}


Tommy was originally from Iraq. When he left his country, his studies at a technological institute were disrupted. He aspired to earn a college degree in the United States but was busy running his own business. At the time of the study, Tommy had been in the program for about a year and had earned an associate degree. Danny was originally from Bhutan but left as an infant and spent much of his life in Nepal. He arrived in the U.S. with his family where he completed high school and some college coursework before dropping out to work full-time in order to support his parents. Danny had been at Pair for about four months. Yannick was from Burkina Faso where he had earned a bachelor's degree. When he arrived in the U.S., his academic credentials were not recognized by local employers. After taking classes online and running into financial barriers, Yannick joined Pair. At the time of the study, he had studied at Pair for about six months.

\section{Data Collection and Analysis}

Each participant was interviewed twice over a two-week period using semi-structured protocols that were adapted through an iterative process as data were collected (Merriam, 1998). The first interview focused on the participant's past experiences with education and the second interview focused on the participant's experiences in the CBE program (Seidman, 2013). In addition, the participants' two academic coaches were interviewed. Interviews ranged from 35 to 85 minutes and were audio-recorded. The interviews were then transcribed verbatim by the head researcher.

Group study sessions and staff meetings were observed over the two weeks. Observations provided an opportunity to learn more about the structure of the program, the goals, and the available supports. Observations ranged between 30 minutes to three hours. Finally, each participant wrote an entry letter describing why they wanted to be in the program, and these letters were collected and coded to provide more insight into each participant's experiences before the program and motivation for pursuing a college degree. 
Data were coded through a combination of inductive and deductive processes (Saldaña, 2016). First, the interviews, letters, and field notes were coded for references to barriers to education and support received from the program. Using constant-comparative analysis, codes were consolidated into common themes (Lincoln \& Guba, 1985; Merriam, 1998). After identifying and defining preliminary codes, the data were revisited using emergent coding to identify any salient themes that had been overlooked in the first coding cycle. Once a final list of codes was determined, we read through the data sources again applying the finalized codes.

\section{Findings}

All three participants held aspirations to complete college and expressed gratitude for the program in providing them a dream that they had felt was out of reach. Entering into the Pair program gave them new hope in these aspirations and they all felt supported in their academic pursuits in numerous ways. The most common forms of support were flexibility and academic coaching. For the illustrations below, we used verbatim quotations, omitting vocal fillers and repetitions where necessary for clarity.

\section{Flexibility: "It Depends on Your Time."}

One of the main benefits of the program was the flexible design. Participants shared that, before entering Pair, they had felt constricted by conflicting priorities. For Tommy, this was owning his own business. Both Danny and Yannick were working two full-time jobs to provide for their families. Danny had taken some college courses previously, and after dropping out, found it increasingly difficult to return to school. As responsibilities accumulated, Danny found the idea of returning to school nearly impossible. As expectations grew, so did the responsibilities. Danny dropped out of college more than once in order to work multiple jobs and provide for his extended family. For example, after living in protracted situations for more than a decade, home ownerships represented stability and permanence. This was an important dream for his parents, so Danny took on multiple jobs. However, with 
homeownership, additional bills and responsibilities accrue. For all three participants, the flexibility within the Pair design made it easier to fit school back into their lives. The online format removed a significant obstacle to college-schedules. In the absence of a traditional classroom structure, it became easier to fit school in around other priorities. Danny explained:

When you have responsibilities, you have stress. When you have stress, you can't focus on these studies. So once that thing is taken out and divided into parts, it relieves you and give you like lightening which will focus on the studies.

The online format of the program removed a structural barrier to college and, through that, renewed aspirations of getting a college degree.

Allowing students to work within their own timeframe also increased the motivation of participants. As Tommy explained, "My job, my family, schedules, it fit this program, cause in this program you do what you can do. There are no absences, nothing, whenever you have time there is a project you can work on." The project-based rather than time-based format further increased student motivation since they could see how they work translated directly into progress in the program. Yannick explained:

When I mastered it, I was so happy and then I came, finished, to look on this one. Even sometimes I sit down with my computer. I open this one and I go back and the first one I learn everything I did. I'm so happy about this project. I love it.

Yannick's mastery on past projects served to motivate him as he continued through subsequent units. The design of the CBE program renewed both long-term aspirations to obtain a college degree, as well as short-term motivation to engage in the challenges presented in each project.

\section{Academic Coaching: "They Support You Every Day."}

Coupled with the online component of Pair, participants also had access to academic coaches who were an essential resource for all three participants. In fact, for Danny, the coaches were what set 
Pair apart from other college programs: "You know and that's the important part of [Pair], they support you." The participants particularly appreciated the availability of the head coach, who had time to work with them on projects, even at late hours. Given the individualized nature of Pair, the additional, inperson support was essential in helping the participants navigate the academic expectations of the program.

Moreover, academic coaching helped students feel more connected overall. Danny explained: "Since I am in the program, the way this program supported me, I was encouraged by the support and the care of this group. This program gave it to me." For Danny, the support offered by the coaches surpassed merely academic by also encouraging him as he progressed through the competencies. Danny entered Pair with the belief that he could not complete the program, but in nurturing his growth through both support and care, the academic coaches and peers helped him develop greater selfefficacy.

Academic coaching was particularly successful in this study because the coaching went beyond academics. Coaching involved motivation, regular check-ins, and problem-solving with classwork but also with financial aid and registration. This helped alleviate common informational barriers. A prevalent barrier was financial aid. Yannick, for example, had been caught by surprise by an overly complicated aid system that left him in debt and without a college degree for several years: "I cannot go to school. I have to pay this [bill]. I have to finish paying this one. Ok, I'm going to go work two fulltime [jobs]." In contrast, Yannick worked with an academic coach from the time he decided to enroll. This allowed him to build trust in the program but also have help navigating common financial obstacles.

The participants also had to develop new ways of understanding how college worked (college knowledge), particularly within a new cultural setting and format. The support provided by the academic coaches was essential in developing this knowledge. Participants explained that towards the beginning of the program, they often met with coaches to understand assignments and feedback. Tommy 
explained: "Sometimes when you have a problem and it's not exactly what they want, you waste all the time, a lot of time. Until you meet with [the coach], or you meet with someone else to explain to you." Understanding what the expectations were in the CBE context was essential to mastering projects, and the academic coaches helped acclimate students to the new college setting.

Finally, academic coaches helped the participants develop concrete academic skills such as grammar, writing styles, and citations as well as new ways of thinking. For example, Yannick learned how to make citations with the help of a coach: "[She] helps me a lot too, for the citations, everything." Tommy also struggled with inherent expectations about ways of thinking in college. It was not always language and writing skills, but rather learning how to think and write like an academic where Tommy

struggle the most: "This is our level of education, this is how we understand it. But it's not exactly what they want." Again, academic coaches served as an important bridge between what academic skills and knowledge participants had when they entered, and what they would need to succeed in the CBE program.

\section{Discussion}

Findings from this case study showed how Pair was effective as a result of both the CBE model and the in-person wrap-around support provided. This supports previous research that has shown that the CBE model works best when used in a blended model that incorporates on-site support (Russell \& Weaver, 2019). The flexibility, format, and context of the program strengthened the aspirations and motivations of the participants. Overall, the academic coaches provided the support to help participants be successful in college. Academic coaches supported students in developing their academic skills and habits through grammar and writing help, but also by explaining expectations. They provided college knowledge by helping students navigate the program.

Our findings support the ecological college readiness model within a CBE blended learning context. Although the format of Pair differed in many ways from traditional college programs, 
participants in our study spoke of developing in ways that aligned with the key elements of academic preparedness proposed by Arnold et al. (2012). The design of the program, in particular, the academic support paired with the CBE model, helped participants develop several of the key elements of academic readiness within the ecological model of college readiness, including college knowledge, selfefficacy, and academic skills.

Although refugee-background students are often subsumed with linguistically diverse students for research and institutional policies (de Kleine \& Lawton, 2015; Kanno \& Varghese, 2010), our findings highlighted intersections with other student populations, including first-generation and nontraditional. The potential barriers to persistence expressed by the participants align with those for first-generation students (see Babineau, 2018). This suggests that the obstacles the refugee-background students face in pursuit of college credentials are multifaceted. Programs, policies, and research need to treat them as such. To do otherwise would fail to support refugee-background students in the more effective forms. A key reason that Pair was successful in supporting the participants was that the support of academic coaches transcended purely academic boundaries. Group sessions built community while the academic coaches developed supporting relationships with the participants, and in doing so, promoted selfefficacy. Furthermore, the CBE format helped each participant overcome common barriers to higher education. By offering a self-paced design, the participants in this study were better able to balance competing priorities with their studies. Furthermore, the self-paced design allowed students to more quickly complete competencies where they felt most confident and to focus on areas where they needed additional skills, knowledge, or language support. Finally, academic coaching, which began alongside enrollment, provided access to the needed information in order to overcome informational barriers.

\section{Limitations and Future Directions}


As with all research, this study had limitations and delimitations. First, the study was limited to a small sample both by the case study design and the relatively new application of CBE with refugeebackground students in the United States. Second, there was a larger enrollment of male students in the program. This made achieving gender parity difficult. Future research should expand the sample size, particularly by examining the experiences of female students who may experience distinct external pressures. Third, the study was conducted over two weeks, which limited the amounts and types of data that could be collected. Future research should look longitudinally at the professional and economic outcomes for students.

Although this study focused on refugee-background students, the findings suggest that the obstacles faced by this population share similarities with other student populations (first-generation, nontraditional, etc.). Future research is needed to understand the potential benefits of this program structure with other student populations.

\section{Implications and Recommendations}

Refugees often rebuild their lives in the US from a position of poverty that creates additional barriers to college, such as cost and conflicting priorities (Batalova et al., 2008). To meet the needs of refugee-background students, colleges need to develop flexible programs that combine a path to a degree with a combination of online learning, in-person support, and community building. Colleges should consider implementing competency-based programs that allow students to progress at their own pace with access to the resources and supports of the college. One of the strengths of Pair was that it made online learning a personal experience. Even though the coursework was online and asynchronous, participants had to build relationships with coaches and fellow students. The academic coaches were particularly valuable to the participants because of the flexibility they offered. In addition to scheduled meetings, academic coaches would meet with students throughout the week as needed and were also 
available by phone or email at any time. For academic coaching to be most effective, it needs to be available when students are.

\section{Conclusion}

Pair is effectively addressing a need for innovative reform in the traditional higher education system to better accommodate the needs of refugees who often struggle to complete their degree on time, or at all, in the typical college settings. In doing so, Pair was successful in helping refugeebackground students overcome common barriers to college. When barriers can be overcome, these participants demonstrated that they could not only be successful in college but thrive. All three participants were nearing the completion of an associate's degree with their sights set on the bachelor's program.

Although earning an accredited college degree was the participants' ultimate goal of enrolling at Pair, it is worthy to note a few additional observed advantages Pair provided. The project-based nature of the program meant that the participants had some first-hand experience with real-world situations, which could effectively prepare them to navigate professional challenges and avoid uncertainties. The mastery of competencies requirement by which students are required to submit A-level work is an assurance that there is no sacrificing academic rigor or compromising learning outcomes. Also, Pair is designed to charge enrollment tuition by time in the program, not per course or credit-hour. This additional feature helps refugees leverage their motivation to graduate more efficiently, as a result, save time and resources. The students who participated in the study have all graduated with no debt $-a$ remarkable milestone more likely to set them up for further accomplishment. The success of these students demonstrates how deficit narratives are driven by structures, not students. When given the opportunity and support, all three participants were able to flourish in their college studies and reach a goal they had long seen as out of reach. 


\section{Author Note}

Meagan A. Hoff, PhD, is a Professor of English at Collin College in McKinney, TX. She recently graduated from the Developmental Education Program at Texas State University. Her research focuses on the intersections of language, literacy, and college readiness, particularly for students from refugee backgrounds.

Khaleel Shreet is a doctoral candidate in the Educational Leadership Program at Southern New Hampshire University. He also works as Senior Coach and Director of the New Hampshire Program at Duet. His research examines the relationship between emotional intelligence and student success within competency-based education programs. His research focuses on nontraditional learners and examines ways to increase access to high quality higher education.

\section{References}

Arnold, K. D., Lu, E. C., \& Armstrong, K. J. (2012). The case for a comprehensive model of college readiness. ASHE Higher Education Report: The Ecology of College Readiness, 38(5), 1-10. https://doi.org/10.1002/aehe.20005.

Babineau, K. (2018). Closing the gap: An overview of the literature on college persistence and underrepresented populations. Cowen Institute.

Bajwa, J. K., Couto, S., Kidd, S., Markoulakis, R., Abai, M., \& McKenzie, K. (2017). Refugees, higher education, and informational barriers. Refuge, 33(2), 56-65.

Bandura, A. (1997). Self-efficacy: The exercise of control. W.H. Freeman. 
Batalova, J., Fix, M., \& Creticos, P. A. (2008). Uneven progress: The employment pathways of skilled immigrants in the United States. National Center on Immigrant Integration Policy, Migration Policy Institute.

Cañado, M. L. P. (2013). Introduction and overview. In M. L. Pérez Cañado (Ed.), Competency-based language teaching in higher education (pp. 1-18). Springer. https://doi.org/10.1007/978-94007-5386-0_1

Capps, R. \& Fix, M. (2015). Ten facts about U.S. refugee resettlement: Fact sheet. Migration Policy Institute. https://www.migrationpolicy.org/research/ten-facts-about-us-refugeeresettlement?gclid=CjOKCQjwhvf6BRCKARIsAGI1GGj5MDuhovxuhsMz8j8nFBkpxb04w29CxLhhFkOt7r_Oc2p2g2HuScaAjHOEALw_wcB

Castaño Muñoz, J., Colucci, E., \& Smidt, H. (2018). Free digital learning for inclusion of migrants and refugees in Europe: A qualitative analysis of three types of learning purposes. The International Review of Research in Open and Distributed Learning, 19(2), 1-22.

https://doi.org/10.19173/irrodl.v19i2.3382

Conley, D. T. (2005). College knowledge: What it really takes for students to succeed and what we can do to get them ready. Jossey-Bass.

Conley, D. T. (2010). College and career ready: Helping all students succeed beyond high school. JosseyBass.

Crea, T. M. (2016). Refugee higher education: Contextual challenges and implications for program design, delivery, and accompaniment. International Journal of Educational Development, 46, 12-22. https://doi.org/10.1016/j.ijedudev.2015.11.005

de Kleine, C., \& Lawton, R. (2015). Meeting the needs of linguistically diverse students at the college level [White Paper]. College Reading and Learning Association. https://www.crla.net/images/whitepaper/Meeting_Needs_of_Diverse_Students.pdf 
Elam, S. (1971). Performance-based teacher education. What is the state of the art? American Association of Colleges for Teacher Education.

Evans, W. \& Fitzgerald, D. (2017). The economic and social outcomes of refugees in the United States: Evidence from the American Consumer Survey. National Bureau of Economic Research.

Gervais, J. (2016). The operational definition of competency-based education many academic institutions and accreditation agencies because it links theory to. Competency-Based Education, 1, 98-106. https://doi.org/10.1002/cbe2.1011.

Hernen, T. A. (2016). Re-inventing remedial reading in the 21st century: A review of the benefits and challenges of a hybrid remedial reading course. HETS Online Journal, 6, 114-37.

Hoff, M. A. (2020). "But it's hard for a refugee": Transitioning to postsecondary literacy practices after forced migration [Unpublished doctoral dissertation] Texas State University.

Kanno, Y., \& Varghese, M. M. (2010). Immigrant and refugee ESL students' challenges to accessing fouryear college education: From language policy to educational policy. Journal of Language, Identity, and Education, 9, 310-328. https://doi.org/10.1080/15348458.2010.517693

Kerwin, D. M. (2011). The faltering US refugee protection system: Legal and policy responses to refugees, asylum seekers, and others in need of protection. Migration Policy Institute. https://www.migrationpolicy.org/research/faltering-us-refugee-protection-system

Krauss, S. M. (2017). How competency-based education may help reduce our nation's toughest inequities. Lumina Issue Papers. Lumina Foundation. http://hdl.handle.net/10919/83258

Laitinen, A. (2012). Cracking the credit hour. New America Foundation and Education Sector. https://files.eric.ed.gov/fulltext/ED540304.pdf

Lincoln, Y. S., \& Guba, E. G. (1985). Naturalistic Inquiry. SAGE. 
McBrien, J. L. (2005). Educational needs and barriers for refugee students in the United States: A review of the literature. Review of Educational Research, 75(3), 329-364.

doi:10.3102/00346543075003329

Merriam, S. B. (1998). Qualitative research and case study applications in education: Revised and expanded from case study research in education. Jossey-Bass.

Morrice, L. (2013). Refugees in higher education: Boundaries of belonging and recognition, stigma and exclusion. International Journal of Lifelong Education, 32(5), 652-668. https://doi.org/10.1080/02601370.2012.761288

Perry, K. H., \& Mallozzi, C. A. (2011). “Are you able ... to learn?": Power and access to higher education for African refugees in the USA. Power and Education Volume, 3(3), 249-262. https://doi.org/10.2304/power.2011.3.3.249

Russell, C. \& Weaver, N. (2019). Reaching refugees: Southern New Hampshire University's project-based degree model for refugee higher education. In E. Sengupta \& P. Blessinger (Eds.), Language, teaching and pedagogy for refugee education. Innovations in Higher Education Teaching and Learning (vol. 15, pp.157-180). Emerald Publishing.

Saldaña, J. (2016). The coding manual for qualitative researchers (3rd ed.). SAGE.

Seidman, I. (2013). Interviewing as qualitative research: A guide for researchers in education and the social sciences. (4th ed). Teachers College Press.

Shapiro, S., \& MacDonald, M. T. (2017). From deficit to asset: Locating discursive resistance in a refugeebackground student's written and oral narrative. Journal of Language, Identity and Education, 16(2), 80-93. https://doi.org/10.1080/15348458.2016.1277725

United Nations High Commissioner for Refugees (UNHCR). (2016). Missing out: Refugee education in crisis. http://www.unhcr.org/57d9d01d0 
Uptin, J., Wright, J., \& Harwood, V. (2016). Finding education: Stories of how young former refugees constituted strategic identities in order to access school. Race Ethnicity and Education, 19(3), 598-617. https://doi.org/10.1080/13613324.2014.885428

U.S. Department of Education. (2013). Applying for Title IV eligibility for direct assessment (competencybased) programs. [Dear Colleague Letter, GEN-13-10]. https://ifap.ed.gov/dpcletters/GEN1310.html

U.S. Department of State. (n.d). The reception and placement program. Accessed January 28, 2018 from https://www.state.gov/j/prm/ra/receptionplacement/index.htm

Yang, Y. (2012). Blended learning for college students with English reading difficulties. Computer Assisted Language Learning, 25(5), 393-410. https://doi.org/10.1080/09588221.2011.597767.

Yosso, T. J. (2005). Whose culture has capital? A critical race theory discussion of community cultural wealth. Race Ethnicity and Education, 8(1), 69-91. http://dx.doi.org/10.1080/1361332052000341006

Zeus, B. (2011). Exploring barriers to higher education in protracted refugee situations: The case of Burmese refugees in Thailand. Journal of Refugee Studies, 24(2), 256-276. https://doi.org/10.1093/jrs/fer011 